\title{
Correspondence
}

Korean J Ophthalmol 2020:34(6):491-492 https://doi.org/10.3341/kjo.2020.0098

\section{Tick Infestation of the Upper Eyelid}

\section{Dear Editor,}

We report a rare case of a tick infestation in the eyelid. A 79-year-old woman was referred to our ophthalmologic clinic with the chief complaint of right upper lid discomfort for two days. Slit lamp examination showed a tick firmly attached to the eyelid margin as well as redness and swelling of the eyelid (Fig. 1A). The uncorrected visual acuity was $20 / 30$ in the right and $20 / 20$ in the left eye. The anterior segment was otherwise normal. The tick was $2 \times 4 \mathrm{~mm}$ in size and had 10 legs. The head and mouth parts of the tick stuck to the eyelid were isolated from the surrounding soft tissues using a 26G needle tip, and the whole tick was gently grasped with tooth forceps and completely removed (Fig. 1B, 1C). The patient was referred to the Department of Infectious Medicine for additional work-up. She did not have fever, diarrhea, or fatigue. The serum antibody tests for Hantaan virus, Leptospira, scrub typhus, and severe fever with thrombocytopenia syndrome (SFTS) were all negative. The complete blood count was normal. The patient was prescribed $100 \mathrm{mg}$ of doxycycline for 1 week as prophylaxis. The tick genus was identified as Ixodes species. At 1 week of removal, the eyelid healed without any signs of complications (Fig. 1D).

To date, approximately 20 cases of tick infestation of the eyelid have been reported, and only one previous case was reported in South Korea [1]. Elderly patients in rural areas
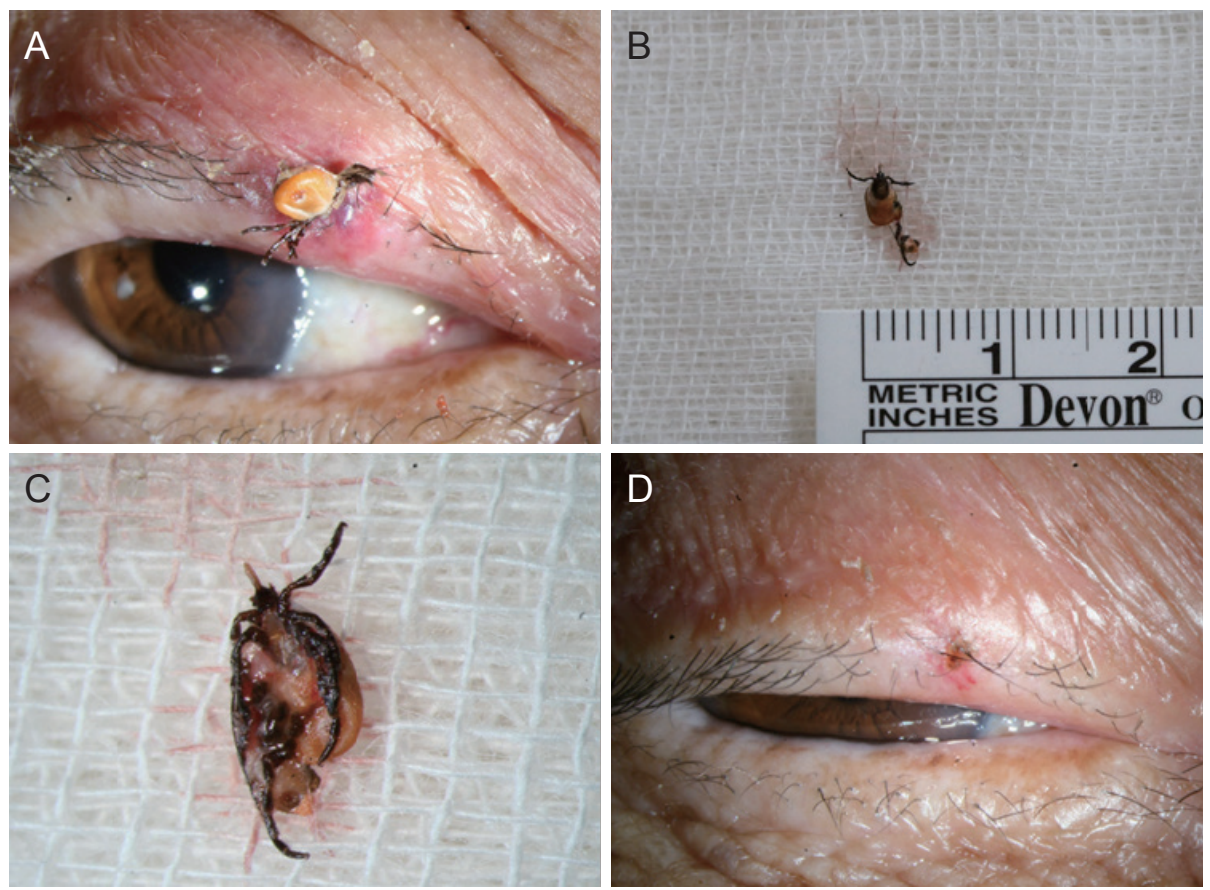

Fig. 1. Clinical photographs of this case (A) Tick infestation on the right upper eyelash margin. (B) A tick after removal (dorsal surface). (C) A tick after removal (ventral surface). (D) Healed eyelid at 1 week after tick removal. Informed consent was obtained from the patient for the publication of the clinical photographs.

Received: July 31, 2020 Accepted: August 14, 2020

(C) 2020 The Korean Ophthalmological Society

This is an Open Access article distributed under the terms of the Creative Commons Attribution Non-Commercial License (http://creativecommons.org/licenses /by-nc/3.0/) which permits unrestricted non-commercial use, distribution, and reproduction in any medium, provided the original work is properly cited. 
are particularly vulnerable because of higher chances of exposure. The salivary secretions of ticks contain anesthetic agents, anti-hemostatic, anti-inflammatory, and immunomodulatory substances, which can delay the diagnosis $[2,3]$. As in the present case, the tick infestation of the eyelid can go undetected for several days due to decreased pain that is unproportioned to the deep tissue invasion [2]. A forceful removal with forceps may increase the risk of release of toxins from the stressed tick or retained tick mouthparts $[1,3]$. Remnant body parts of the tick can lead to granuloma or abscess formation [2]. Therefore, en bloc resection with punch biopsy has been recommended because of the possibility of incomplete removal [1-3]. However, this method is invasive and cosmetically less satisfactory. In this case, the simple removal of tick was considered possible as the patient had no pain due to anesthetic agents secreted by the tick. Simple removal with isolation of the tick using a $26 \mathrm{G}$ needle can be a less inavasive alternative method to en bloc resection, and it can be easily performed in the office without losing eyelid tissue. Ticks are wellknown vectors in the transmission of infectious diseases, such as Lyme disease, Leptospira, scrub typhus, and SFTS. Annually, about 40 to 80 cases of SFTS have been reported in South Korea since 2013, with a mortality rate of $32.6 \%$ [4]. Therefore, general evaluation of tick bites is also highly suggested.

\section{Yeon Jeong Lee}

Department of Ophthalmology, Kangwon National University Hospital, Kangwon National University School of Medicine,

Chuncheon, Korea

\section{Eun-Taek Han}

Department of Medical Environmental Biology and Tropical Medicine, Kangwon National University School of Medicine,

Chuncheon, Korea
Sang Beom Han

Department of Ophthalmology, Kangwon National University Hospital, Kangwon National University School of Medicine, Chuncheon, Korea

E-mail:sbhan@kangwon.ac.kr

\section{Conflict of Interest}

No potential conflicts of interest relevant to this article were reported

\section{Acknowledgements}

This study was supported by the Basic Science Research Program through the National Research Foundation of Korea (NRF) funded by the Ministry of Education (grant no. NRF-2017R1D1A1B03029983).

\section{References}

1. Park J, Suh E. Tick infestation of the eyelid and removal with forceps and punch biopsy. J Craniofac Surg 2016;27:2098100.

2. Price KM, Woodward JA. Management of tick infestation of the eyelid. Ophthalmic Plast Reconstr Surg 2009;25:32830.

3. Bowes OM, Legg G, Haines R, Vardy SJ. Tick infestation of the upper eyelid. Can J Ophthalmol 2015;50:e39-40.

4. Choi SJ, Park SW, Bae IG, et al. Severe fever with thrombocytopenia syndrome in South Korea, 2013-2015. PLoS Negl Trop Dis 2016;10:e0005264. 